\title{
Aortic Arch Aneurysm. Compression Respiratory Complications as a Vital Indication for Emergency Surgery.
}

\author{
Husam H. Balkhy
}

The University of Chicago Medical Center

\section{Roman Komarov}

Sechenov University: Pervyj Moskovskij gosudarstvennyj medicinskij universitet imeni I M Secenova

\section{Vladimir Parshin}

Sechenov University: Pervyj Moskovskij gosudarstvennyj medicinskij universitet imeni I M Secenova

\section{Alisher Ismailbayev}

Sechenov University: Pervyj Moskovskij gosudarstvennyj medicinskij universitet imeni I M Secenova

\section{Nikolay Kurasov}

Sechenov University: Pervyj Moskovskij gosudarstvennyj medicinskij universitet imeni I M Secenova

\section{Olga Keyko}

Sechenov University: Pervyj Moskovskij gosudarstvennyj medicinskij universitet imeni I M Secenova

\section{Ivan Ivashov ( $\square$ I.Ivashov@yandex.ru )}

Sechenov University: Pervyj Moskovskij gosudarstvennyj medicinskij universitet imeni I M Secenova https://orcid.org/0000-0001-6503-789X

\section{Alexander Danachev}

Sechenov University: Pervyj Moskovskij gosudarstvennyj medicinskij universitet imeni I M Secenova

\section{Case report}

Keywords: Thoracic aortic aneurysm, aorta-tracheal fistula, airway compression, recurrent communityacquired pneumonia, simultaneous surgical intervention

Posted Date: January 15th, 2021

DOI: https://doi.org/10.21203/rs.3.rs-145199/v1

License: (1) (1) This work is licensed under a Creative Commons Attribution 4.0 International License. Read Full License 


\section{Abstract}

Background: giant thoracic aortic aneurysms and aortic arch dissections are accompanied by high mortality rates, cardiac and neurologic events and pulmonary complications. Aorta-tracheal fistula and tracheobronchial compression are formidable and well-known complications of aneurysms of the thoracic aorta. Twenty-two percent of aneurysms that size $>6 \mathrm{~cm}$ are ruptured with $80 \%$ mortality rate.

Case presentation: a 56-year-old man with severe multivascular coronary artery injury and giant aneurysm of ascending aorta and aortic arch, complicated by respiratory failure and recurrent community-acquired pneumonia. Preoperative chest CT showed giant partially-thrombosed ampullary false aneurysm of ascending aorta, aortic arch and initial part of the thoracic aorta, $80 \times 100 \times 65 \mathrm{~mm}$ in size. Patient successfully underwent simultaneous surgical intervention with artificial blood circulation, the total time of cardiopulmonary bypass was 190 minutes.

Conclusions: tracheobronchial compression syndrome with the aortic arch aneurysms is one of the urgent conditions that needs emergency surgery. Urgent indications for surgery in such cases include both significant size of the aneurysm and high risk of rupture, as well as potential for developing critical respiratory failure and recurrent nonresolving pneumonias. Preoperative CT enables to find out the exact location and evaluate the degree of airway compression, which determines further intraoperative actions. We recommend to use bronchoscopy at all steps of treatment of such patients, from intubation in operating room to extubation in intensive care unit. Thus, aggressive surgical tactics along with careful pre-operative diagnostic are the key to success and the only chance for such patients.

\section{Background}

Aneurysms and aortic arch dissections are associated with high mortality rates, cardiac and neurologic events, pulmonary complications in either natural course or surgery treatment (1). In spite of advancing cardiac surgery, improvement of anesthesiology, simultaneous aortic arch replacement and coronary arteries are accompanied by high operative mortality and worsened intraoperative and postoperative prognosis (2). Tracheobronchial compression is a dangerous and well-known complication of aneurysms of the thoracic aorta. It generally occurs because of the close anatomic relationship of the aortic arch to the trachea and the left main bronchus. Clinical manifestations are varying from asymptomatic conditions to acute respiratory failure (3). (Many of the patients were either asymptomatic or otherwise had catastrophic life-threatening events). Pulmonary complications, as a result of vascular compression, can lead to tracheomalacia, recurrent pneumonias and aorta-tracheal (bronchial) fistulas. Therefore, the treatment approach significantly changes and the prognosis worsens (4).

\section{Case Presentation}

We describe a case of a 56-year-old man with severe multivascular coronary artery injury and giant aneurysm of ascending aorta and aortic arch, complicated by airway compression, aorta-tracheal fistula 
and recurrent community-acquired pneumonia. He successfully underwent simultaneous surgical intervention.

A 56-year-old man was referred because of breathlessness on exertion and at rest, prolonged cough with bloody sputum production and hoarseness. His anamnesis reports that he has been suffered hypertension for the last 10 years (the highest blood pressure recorded was $250 / 130 \mathrm{~mm} \mathrm{Hg}$ ) and has a long history of smoking (30 years, smoking index 30 pack-year). Three years before he suffered from ischemical cerebral circulation disorder in the middle cerebral artery district with complete regression of focal neurological symptoms. Over the last two years he noted a decrease in exercise tolerance, increased breathlessness and hoarseness. He was thought to have chronic bronchitis, however, no effect of treatment antibacterial, mucolytic and local therapy was observed.

The patient was immediately hospitalized to intensive care unit as the clinical symptoms of respiratory distress increased and stridor appeared. Preoperative chest CT (Fig. 1) showed giant partially-thrombosed ampullary false aneurysm of ascending aorta, aortic arch and initial part of the thoracic aorta, $80 \times 100 \times$ $65 \mathrm{~mm}$ in size (more pronounced on the lower wall of aortic arch).

However, the size of the contrasting part of the aneurysm was $66 \times 67 \times 45 \mathrm{~mm}$, and the area of arising branches of brachiocephalic arteries was not involved in the process. It should be mentioned that left main bronchus, left pulmonary artery and the trachea (as in compartment syndrome over the bifurcation) were strongly presses and pushed by aneurysm, less pressed were left pulmonary veins, esophagus and azygos vein. Moreover, CT revealed also bilateral multisegmental pneumonia.

The patient thus had indications for aneurysmectomy. However, because of coexisting disease bronchopulmonary infection and diagnosed community-acquired bilateral pneumonia, surgical operation was postponed. Although therapy was carried out, and temporary regression of fever and reduction of respiratory distress were observed, control lung CT showed new centers of infiltration, increase of airway compression with left main bronchus occlusion. Recurrent pneumonia against the trachea drainage tube disorder was diagnosed.

\section{Operation}

Taking into account the supra-bifurcation compression of the trachea, as well as compression of the left main bronchus, tracheal intubation was performed using bronchoscopy. Given the complete compression of the trachea bifurcation and left main bronchus, at the initial stage, only the right lung was ventilated.

The right subclavian artery was isolated with parallel preparation of the great saphenous vein. After a median sternotomy, LITA was isolated. Opening of the pericardium reveals enlargement of the ascending aorta up to $5 \mathrm{~cm}$, aortic arch aneurysm 10-12 cm in diameter with the involvement of the initial part of the thoracic aorta, compression of the branches of the pulmonary trunk, trachea and left main bronchus. Artificial blood circulation was performed by cannulating the right subclavian artery, right atrium with a two-level cannula. In order to reduce the time of myocardial ischemia, the distal anastomoses of the 
coronary artery bypass were performed in parallel perfusion during the cooling process (target temperature $26^{\circ} \mathrm{C}$ ). The next step was to isolate the ascending aorta, and the aneurysmal sac was delicately separated from the branches of the pulmonary artery. After clamping, the aorta was opened with a transverse incision $1.5 \mathrm{~cm}$ above the sinotubular zone, blood cardioplegia was performed antegrade at the mouth of the coronary arteries using the Calafiore method (for $3 \mathrm{~min}$ ). In addition, given the critical stenosis of the coronary arteries, the cardioplegic solution was injected additionally through the previously imposed autovenous shunts for 2 minutes. In the lumen of the dilated part of the ascending aorta, signs of rupture and a small number of thrombotic masses were revealed. The brachiocephalic trunk was clamped, visceral arrest and monohemispheral perfusion of the brain (under the control of cerebral oximetry) began. The aortic arch is cut off from the brachiocephalic trunk, left common carotid and left subclavian arteries. After opening the aneurysmal sac formed by the posterior wall of the aortic arch and the initial section of the descending aorta, multiple signs of intimal rupture were revealed in the lumen, as well as massive thrombotic masses (up to $400 \mathrm{~g}$ ). The aneurysmal sac was excised, the aneurysm bed in the posterior mediastinum was thoroughly sanitized with antiseptics, and the affected aorta was cut off from its thoracic region within the "healthy" tissues. During the revision of the trachea, no signs of tracheomalacia were detected, however, an aorta-tracheal fistula up to $2 \mathrm{~cm}$ long was found, temporarily damped with an antiseptic napkin.

The next step was the total prosthetics of the aortic arch using a synthetic multi-branch prosthesis No. 28 , the visceral arrest was completed, which was 60 minutes. Further, the end of the prosthesis is anastomosed with the ascending aorta by the type of supracoronary prosthetics, and proximal anastomoses with autoveins are formed. The time of aortic clamping was 100 minutes, cardiac activity was restored independently, mammary-coronary bypass grafting was performed on parallel perfusion during warming of the patient.

After exposure of the trachea and its separation from the surrounding tissues, under the control of bronchoscopy, suture plasty of the postero-lateral wall defect was performed with 5 separate vicryl 4/0 sutures. Tightness control was also carried out using bronchoscopy. After decompression of the airways, the endotracheal tube was repositioned - the left lung was successfully included. The total time of cardiopulmonary bypass was 190 minutes. Intraoperative view after reconstruction (Fig. 2).

The patient was extubated 2 days after surgery, the duration of observation in the intensive care unit was 48 hours. It should be noted that the patient's extubation was performed after preliminary control bronchoscopy for tightness of the trachea and patency of the left main bronchus. The patient was discharged on the 14th day after the operation, with satisfactory echocardiography, laboratory tests and no data for respiratory, heart and coronary insufficiency. Dynamic computed tomography did not reveal infiltrative changes in the lungs and mediastinum.

At the control examination 6 months after the operation, the patient's somatic condition corresponded to functional class 1 by NYHA. According to CT of the chest, the area of reconstruction of the aortic arch is consistent (Fig. 3). Patency of the trachea and main bronchi has been restored. 


\section{Discussion And Conclusions}

Determining surgical indications for aortic arch aneurysms. Aortic arch pathologies often pose significant challenges to surgical or endovascular treatment. Conditions affecting the aortic arch relevant to the vascular surgeon include degenerative aneurysms and the acute aortic syndromes (e.g. penetrating ulcers, intramural hematoma and aortic dissections) (5). However, in 2019 EACTS and ESVS published an expert consensus document in which they mentioned/listed less common/rare aortic arch pathologies, such as: arteria lusoria, Kommerell diverticulum, traumatic, infectious, giant-cell and Takayasu's arteritis (6).

The incidence of degenerative aortic arch aneurysms is increasing with advances of imaging. The growth of aortic arch aneurysm is an indolent process with a mean annual growth rate from 0.07 to $0.2 \mathrm{~cm} / \mathrm{y}(7)$. Main risk factors include increasing age, female sex, presence of chronic obstructive pulmonary disease, hypertension and positive family history (8). However, no researches specifying in aortic arch or rate of expansion or the risk of true aneurysms rupture are presented. Scientists from Yale University report that annual growth rate of aorta is about $1 \mathrm{~cm} / \mathrm{y}$ and for aneurysms exceeding $6 \mathrm{~cm}$ in diameter rupture can occur at $6,9 \%$ per year. The annual risk of rupture generally increases with the diameter growth, so they recommend performing operative intervention when the aneurysms measures 5.5-6 cm (9). Moreover, some other scientists state that aneurysm size beyond $6.5 \mathrm{~cm}$ is associated with faster expansion (with an average rate of $2.5 \mathrm{~mm} / \mathrm{y}$ ) and hyperlipidemia (5). Twenty-two percent of aneurysms of that size ruptured with $80 \%$ mortality rate, they note.

Tracheobronchial compression syndrome with the aortic arch aneurysms is one of the urgent conditions that needs emergency surgery (3). There is no accurate data presenting the frequency of this complication, although some researchers suggest $5-10 \%(10)$.

Airway compression syndrome is also an independent predictor of emergency surgery in patients with double aortic arch, arteria lusoria, pulmonary artery sling, and Kommerell diverticulum (11). Most of the authors consider urgent aortic arch surgery the only option for patients with tracheobronchial compression syndrome.

Purpose of separate examination of indications for aortic arch surgical treatment as immediate is related to existing relative contraindications for a surgery in conditions of CPB and visceral arrest in our patient. A giant false aneurysm leads to tracheobronchial compression, which caused bronchial drainage disruption. It resulted in nonresolving community-acquired pneumonia, which a priori complicated periand postoperative prognosis.

The main risks of aortic arch interventions include neurological, cardiac, renal and pulmonary disorders in the early postoperative period. Accordingly, the purpose of preoperational patient preparation is to maximize the levelling of conditions which deteriorate the results of surgery with CPB and visceral arrest (12). 
However, in case of our patient the emergency intervention seems justified, as he had both vascular (thrombosis, rupture and size more than $9 \mathrm{~cm}$ ) and extravasal (tracheobronchial compression syndrome, high degree of respiratory failure and as a result, fever due to pneumonia) indications for aortic arch replacement. Also, considering the respiratory tract compression, complex therapy of pneumonia in this case was not possible. This fact once again indicates the inexpediency and unsuccess of conservative therapy in the tracheobronchial tree block and the justification of urgent surgery.

\section{Ways to improve the results of simultaneous total prosthetic replacement of the aortic arch and coronary}

bypass. Simultaneous coronary arteries bypass graft is performed in $15-30 \%$ of all patients with aortic arch surgeries (13). CABG following the total prosthetic replacement of the aortic arch is considered as significant risk factor of increased operative mortality and morbidity (2). However, in a number of modern works it is suggested that there is no significant difference in mortality rate between patients with and without simultaneous coronary revascularization (14). For this reason, it seems relevant to optimize coronary bypass in this patient cohort via minimizing the period of CPB time and myocardial ischemia.

For that purpose, in our patient's case, distal anastomoses of autoveins with obtuse marginal artery and posterior descending artery of right coronary artery were carried out on parallel perfusion during cooling process and proximal - during warming process.

Further, mammary coronary bypass of anterior interventricular artery was performed on parallel CPB during patient warming.

Chosen approach is confirmed by a number of major studies. For example, Toshihiro Fukui presents a similar order of coronary artery bypass graft in 56 patients who underwent total prosthetic replacement of the aortic arch (2). The fatality rate in the examined group was $3.6 \%$ (2 patients), and it had no connection to follow-up coronary bypass. Postoperative coronary bed CT was performed in 51 patients and revealed complete permeability of all anastomoses. Similar technique of myocardial revascularization in patients with aortic arch pathology is followed by Yokoyama H. (except of the LITA use) (13).

It stands to mention that the use of the LITA graft is controversial in patients with total prosthetic replacement of the aortic arch. Thus, Yokoyama $\mathrm{H}$. did not use these grafts due to the reasons, which include 1) the possibility of cardioplegia administration through free grafts after forming the anastomoses; 2 ) hemodynamic instability after arch replacement (which is not uncommon for this complex operation) can decrease blood flow in small compressed LITA; 3 ) anastomosis of the LSA with the prosthesis can predispose to LITA dissection (13). Whereas, Kuniyoshi et al. used LITA for revascularization of anterior interventricular branch in this group of patients with good permeability indications confirmed by coronaro/shuntography (15). Several authors recommend LITA for coronary bypass in patients undergoing total arch replacement due to the proven long-term permeability of this graft, and also based on evidence that myocardial infarction is one of the main causes of late postoperative death in this patient cohort (13). 
We believe that usage of LITA graft as a conduit is a choice for the anterior interventricular branch revascularization in all patients, including those who need aortic arch surgeries.

\section{Optimization of anesthesiological practices and surgical approach for vascular compression of the} respiratory tract. Trachea intubation, providing of optimal and safe artificial lung ventilation is a significant problem in patients with large aortic arch aneurysms which are accompanied by airway compression. It may be explained by the expressed anatomical distortion due to vascular compression (16). Trachea intubation in such cases can be performed with endotracheal tube with a double lumen on the left or right side if there is significant compression of the entrance to the left main bronchus (17). A number of authors mention the danger of using a left-side double-lumen tube in patients with the compression of the left bronchus trunk bottom, as using of ALV in this method increases the risk of aneurysm rupture. In addition, contraindications for the use of double lumen tubes include anatomical aspects, such as damage of the cardinal or bronchial veins, coarctation and vessel compression by aortic aneurysm (16). Most thematic publications point to the vital importance and effectiveness of intraoperative bronchoscopic monitoring while airway decompression (18). In such cases, the flexible bronchoscope allows to inspect all available areas of the respiratory tract, evaluate the properties of endoluminal tissue of walls and carry out effective direct purification of the remaining excretions after decompression (3).

In case of our patient, we preferred to use a single lumen tube, and trachea intubation was controlled by bronchoscopy. Constant monitoring within the lumen allowed us to control decompression results, and to turn on the left lung after releasing the main trunk of the left bronchus. Distinction of our case is aortatracheal fistula found after aneurysm dissection and complete release of the trachea. Turning to the literature, we found that most modern works describe the successful decompression of the respiratory tract after aneurysmectomy and absence of the need for prosthetics or endovascular repair of trachea and bronchi (19). However, the literature describes the case of tracheomalacia detected intraoperatively after resection of the syphilitic aneurysm of the aortic arch, which was successfully corrected by implantation of a $14 \mathrm{~mm}$ Y-shaped silicone stent explanted after 6 months with complete stabilization of tracheal and main bronchi walls (20). Treatment of irreversible compression lesions of trachea involves straight or step-by-step reconstruction. However, in cases with cardiosurgical patients, these methods may not be applicable due to development of life-threatening respiratory failure. Most authors confirm the effectiveness and safety of implantation of the above-described temporary endotracheal stent as an alternative to reconstructive airway interventions (21). After aneurysmectomy and airway decompression, control bronchoscopy revealed no signs of tracheomalacia, which allowed us to eliminate fistula performing only effective suture plastic of trachea. Therefore, regardless of the presence or lack of integrity of trachea or bronchi wall, for patients of this group we recommend to use bronchoscopy at all stages of treatment, from intubation in the operating room to extubation in the intensive care unit.

Modern view on aortic arch surgery. Since Hans Borst described the "elephant trunk technique" in 1983, many cardiac surgery centers have accumulated enormous experience in performing this operation (22). Over the years, new improvement methods of a complex aortic arch repair were developed and widely 
implemented. The most important developments now include synthetic multi-branch prostheses, homographs, stent grafts, all of which have become commercially available over the past decade (12).

We believe that multi-branch prosthesis has a number of advantages justifying its routine usage in complex aortic arch repair. Thus, there is a potential to minimize the visceral arrest time and the period of myocardial ischemia. In addition, hemostasis significantly improves, and patients with connective tissue diseases potentially reduce their risks of repeated interventions $(23,24)$.

It should be noted that the experience gained in aortic arch surgery allows to identify preferred "candidates" for a particular graft. Thus, some authors recommend implantation of freshly frozen homographs to patients with DeBakey type I aortic dissections and do not recommend their usage for people with Marfan syndrome due to the high risk of reoperations (25). Developing over the last years endovascular and hybrid techniques for implanting stent grafts in the treatment of aortic arch aneurysms may be useful, but they are still associated with a number of technical and economic difficulties, and with the high risk of neurological complications (26).

In case of our patient, use of a synthetic multi-branch prosthesis was the only option. We assume that frozen homografts are preferable to relatively "scheduled" patients, and the endovascular technique in that case didn't allow us to perform airway decompression.

Patients with aortic arch aneurysms may develop an airway compression. Urgent indications for surgery in such cases include both significant size of the aneurysm and high risk of rupture, as well as potential for developing critical respiratory failure and recurrent nonresolving pneumonias. Preoperative CT enables to find out the exact location and evaluate the degree of airway compression, which determines further intraoperative actions. We recommend to use bronchoscopy at all steps of treatment of such patients, from intubation in operating room to extubation in intensive care unit. Surgical planning and accurate preoperative diagnostic are essential to a successful outcome in case of these patients. Simultaneous aortic arch replacement and coronary bypass needs further optimization of time for myocardial ischemia.

Patients with large degenerative aortic arch aneurysms may have airway compression. Urgent indications for intervention in case of such patients include not only the significant size of the aneurysm but also high risk of rupture, and potential for developing critical respiratory failure and recurrent nonresolving pneumonias. Pre-operative CT scan allows to clarify the location and degree of airway compression, which determines further intraoperative tactics. We recommend to use bronchoscopy at all stages of treatment of similar patients - from intubation in the surgery room till extubation in the intensive care. Thus, aggressive surgical tactics along with careful pre-operative diagnostic are the key to success and the only chance for such patients.

Literature data analysis revealed no published cases of $\mathrm{CHD}$ in combination with thoracic aortic aneurysms, with obstructive respiratory complications and aorta-visceral fistulas. Simultaneous aortic arch replacement and coronary bypass require optimization aimed to reduce myocardial ischemia time. 


\section{Abbreviations}

ALV - artificial lung ventilation

CABG - coronary artery bypass grafting

CHD - coronary heart disease

CPB - cardio pulmonary bypass

CT - computed tomography

EACTS - European Association for Cardio-Thoracic Surgery

ESVS - European Society for Vascular Surgery

LITA - left internal thoracic artery

LDA - left descending artery

NYHA - New York Heart Association

$\mathrm{RCA}$ - right coronary artery

\section{Declarations}

Ethics approval and consent to participate:

Sechenov University local ethical committee.

Consent for publication:

Written informed consent was obtained from the patient for publication of this case report and any accompanying images. Upon request, a copy of the written consent is available for review to the Editor-inChief of this journal.

\section{Availability of data and materials:}

Data sharing is not applicable to this article as no datasets were generated or analyzed during the current study.

\section{Competing interests:}

The authors declare that they have no competing interests.

\section{Funding:}


Not applicable.

\section{Authors' contributions:}

Husam H. Balkhy and Komarov Roman decided the surgical approach; Komarov Roman, Parshin Vladimir, Kurasov Nikolay performed surgery; Keiko Olga conducted the treatment of concomitant diseases in this patient; Ismailbayev Alisher, Ivashov Ivan and Danachev Alexander analyzed the literature, interpreted the patient data regarding it, also translated and edited publication. All authors read and approved the final manuscript.

\section{Acknowledgements:}

Not applicable.

\section{References}

1. Valentine RJ, Boll JM, Hocking KM, Curci JA, Garrard CL, Brophy CM, et al. Aortic arch involvement worsens the prognosis of type B aortic dissections. J Vasc Surg [Internet]. 2016;64(5):1212-8. Available from: http://dx.doi.org/10.1016/j.jvs.2016.04.054

2. Fukui T, Shimokawa T, Tabata M, Takanashi S. Outcomes of total aortic arch replacement with coronary artery bypass grafting. Interact Cardiovasc Thorac Surg. 2011;13(3):284-7.

3. Kumar A, Dutta V, Negi S, Puri G. Vascular airway compression management in a case of aortic arch and descending thoracic aortic aneurysm. Ann Card Anaesth. 2016;19(3):568-71.

4. Gelsomino S, Romagnoli S, Dragotto A, Cassai M, Fiorani B, Sorbara C, et al. Multistep endobronchial-endovascular approach in recurrent acute respiratory failure caused by thoracic aneurysm. J Thorac Cardiovasc Surg. 2005;129(6):1436-8.

5. Yiu RS, Cheng SWK. Natural history and risk factors for rupture of thoracic aortic arch aneurysms. J Vasc Surg [Internet]. 2016;63(5):1189-94. Available from:

http://dx.doi.org/10.1016/j.jvs.2015.12.043

6. Czerny M, Schmidli J, Adler S, Van Den Berg JC, Bertoglio L, Carrel T, et al. Current options and recommendations for the treatment of thoracic aortic pathologies involving the aortic arch: An expert consensus document of the European Association for Cardio-Thoracic surgery (EACTS) and the European Society for Vascular Surgery (ESVS). Eur J Cardio-thoracic Surg. 2019;55(1):133-62.

7. Patel HJ, Deeb MG. Ascending and arch aorta pathology, natural history, and treatment. Circulation. 2008;118(2):188-95.

8. Coady MA, Rizzo JA, Goldstein LJ, Elefteriades JA. Natural history, pathogenesis, and etiology of thoracic aortic aneurysms and dissections. Cardiol Clin. 1999;17(4):615-35.

9. Davies RR, Goldstein LJ, Coady MA, Tittle SL, Rizzo JA, Kopf GS, et al. Yearly rupture or dissection rates for thoracic aortic aneurysms: Simple prediction based on size. Ann Thorac Surg. 2002;73(1):17-28. 
10. Cooke JC, Cambria RP. Simultaneous tracheobronchial and esophageal obstruction caused by a descending thoracic aneurysm. J Vasc Surg. 1993;18(1):90-4.

11. Sebening C, Jakob H, Tochtermann U, Lange R, Vahl CF, Bodegom P, et al. Vascular tracheobronchial compression syndromes - Experience in surgical treatment and literature review. Thorac Cardiovasc Surg. 2000;48(3):164-74.

12. Martens A, Beckmann E, Kaufeld T, Umminger J, Fleissner F, Koigeldiyev N, et al. Total aortic arch repair: Risk factor analysis and follow-up in 199 patients. Eur J Cardio-thoracic Surg. 2016;50(5):940-8.

13. Yokoyama $\mathrm{H}$. Aortic arch aneurysm complicated with coronary artery disease: still a surgical challenge? Ann Thorac Cardiovasc Surg. 2002;8(2):62-8.

14. Yokoyama H, Sato Y, Takase S, Takahashi K, Wakamatsu H, Sato Y. Introduction of off-pump coronary artery bypass into aortic arch aneurysm repair: A new solution for the surgical treatment of multiorgan arteriosclerosis. J Thorac Cardiovasc Surg. 2005;129(4):935-6.

15. Kuniyoshi Y, Koja K, Miyagi K, Uezu T, Yamashiro S, Arakaki K, et al. Surgical treatment of aortic arch aneurysm combined with coronary artery stenosis. Ann Thorac Cardiovasc Surg Off J Assoc Thorac Cardiovasc Surg Asia. 2002 Dec;8(6):369-73.

16. Campos JH. Lung isolation techniques for patients with difficult airway. Curr Opin Anaesthesiol. 2010;23(1):12-7.

17. Lohser J, Slinger P. Lung injury after one-lung ventilation: A review of the pathophysiologic mechanisms affecting the ventilated and the collapsed lung. Anesth Analg. 2015;121(2):302-18.

18. Lincoln JC, Deverall PB, Stark J, Aberdeen E, Waterston DJ. Vascular anomalies compressing the oesophagus and trachea. Thorax. 1969;24(3):295-306.

19. Kumeda H, Tomita Y, Morita S, Yasui H. Compression of trachea and left main bronchus by arch aneurysm. Ann Thorac Surg. 2005;79(3):1038-40.

20. Pacini D, Mattioli S, Di Simone MP, Ranocchi F, Grillone G, Di Bartolomeo R, et al. Syphilitic aortic aneurysm: A rare case of tracheomalacia. J Thorac Cardiovasc Surg. 2003;126(3):900-2.

21. Babu MM. Montgomery T-tube for Management of Tracheal Stenosis: A Retrospective Analysis in a Government Hospital of South India. Int J Phonosurgery Laryngol. 2016;6(2):73-7.

22. Shrestha M, Martens A, Krüger H, Maeding I, lus F, Fleissner F, et al. Total aortic arch replacement with the elephant trunk technique: Single-centre 30-year results. Eur J Cardio-thoracic Surg. 2014;45(2):289-96.

23. Shrestha M, Martens A, Behrendt S, Maeding I, Koigeldiyev N, Haverich A. Is the branched graft technique better than the en bloc technique for total aortic arch replacement? Eur J Cardio-thoracic Surg. 2014;45(1):181-7.

24. Di Eusanio M, Schepens MAAM, Morshuis WJ, Dossche KM, Kazui T, Ohkura K, et al. Separate grafts or en bloc anastomosis for arch vessels reimplantation to the aortic arch. Ann Thorac Surg. 2004;77(6):2021-8. 
25. Di Eusanio M, Pantaleo A, Murana G, Pellicciari G, Castrovinci S, Berretta P, et al. Frozen elephant trunk surgery-the Bologna's experience. Ann Cardiothorac Surg. 2013;2(5):597-605.

26. Oztas DM, Canbay C, Onal Y, Beyaz MO, Sayin OA, Barburoglu M, et al. Endovascular Stent Grafting for Aortic Arch Aneurysm in Aortoiliac Occlusive Disease following Aortic Arch Debranching and Aortobifemoral Reconstruction. Case Rep Med. 2017;2017.

\section{Figures}
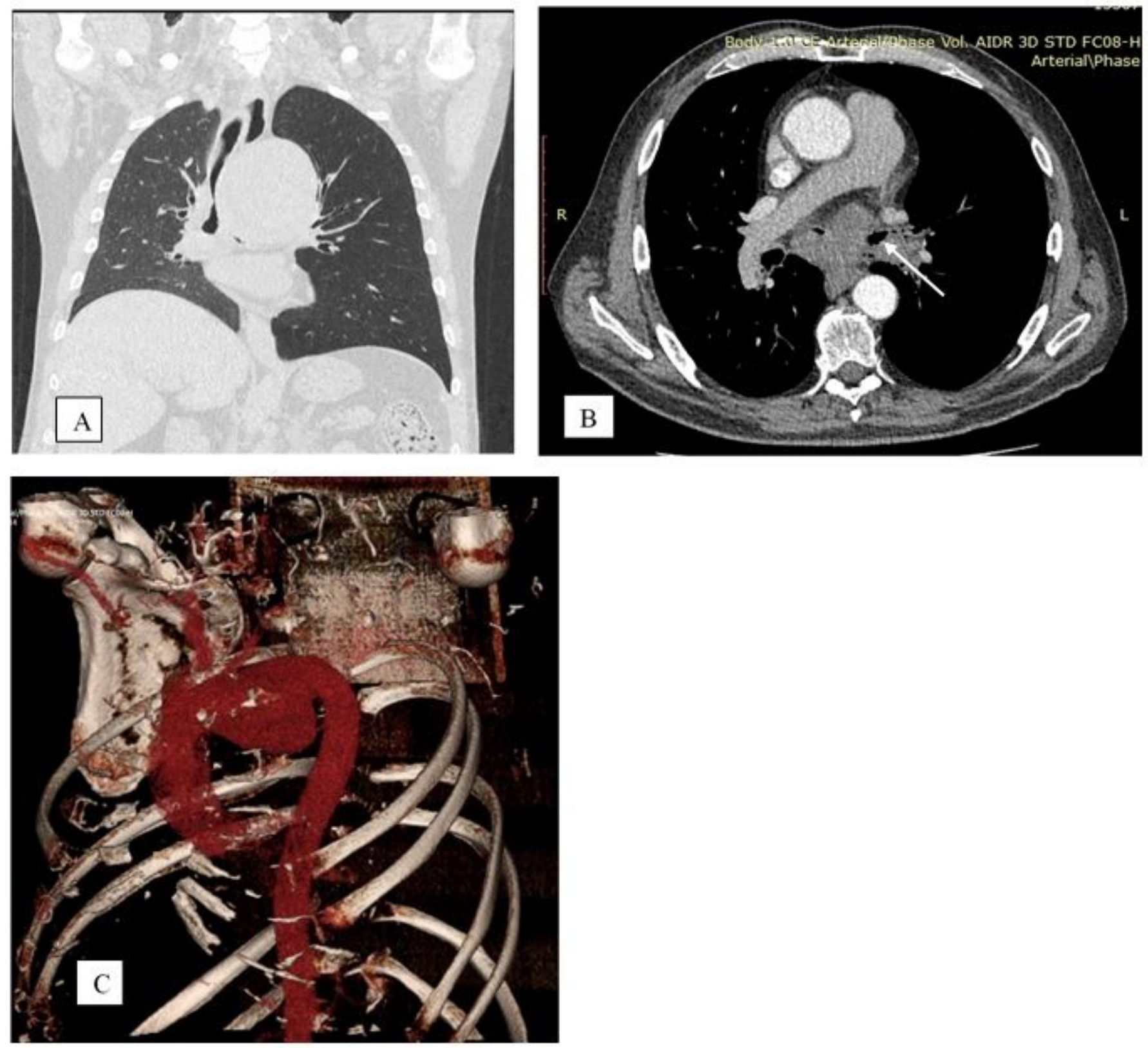

Figure 1

CT-scan: Aneurysm compresses the trachea and left main bronchus. A) Coronal view; B) Axial view (the white arrow indicates the left main bronchus); C) 3D reconstruction 


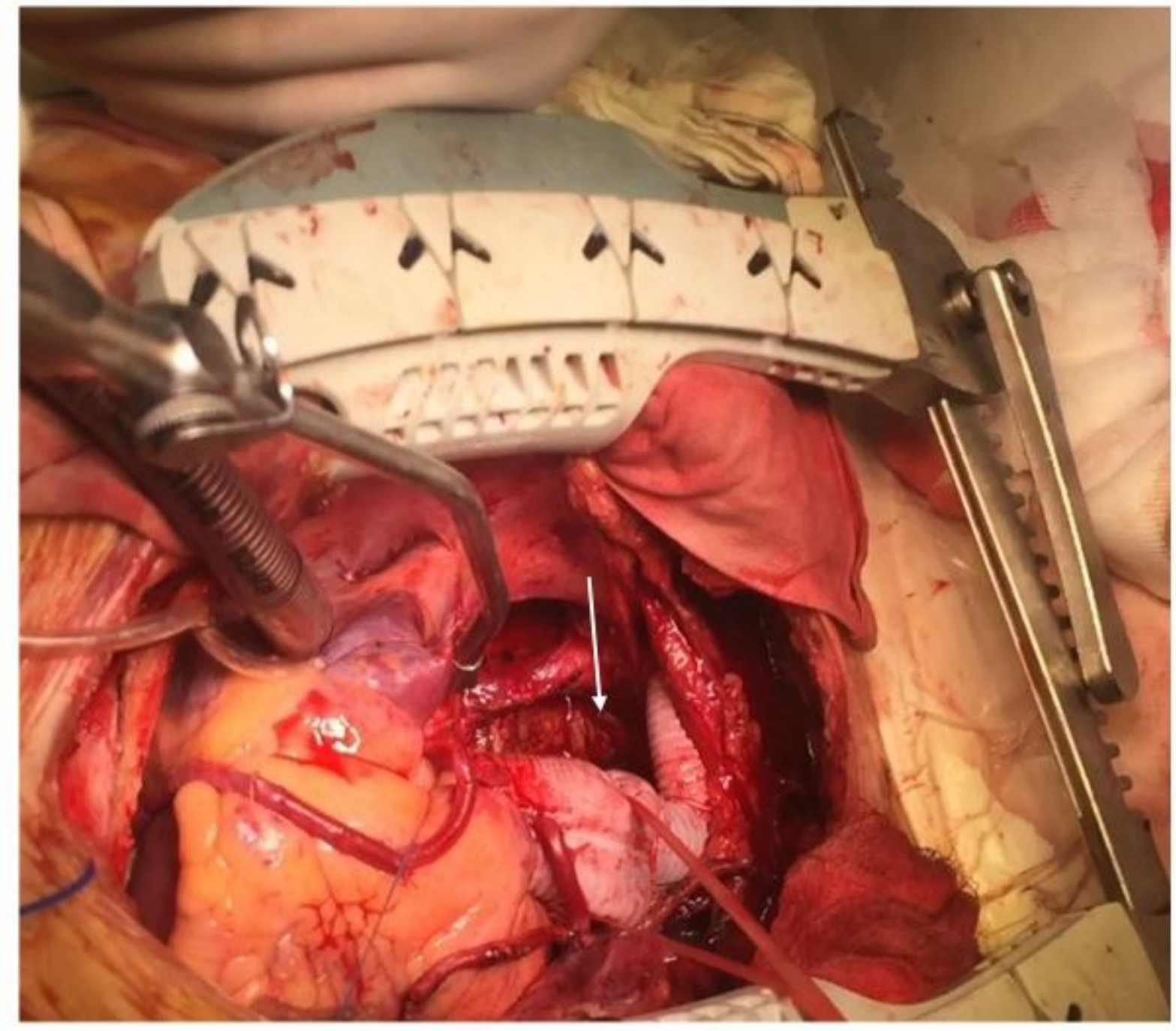

Figure 2

The final view after operation. Thoracic aortic aneurysm replaced with synthetic prosthesis and coronary artery bypass grafting was performed. The arrow indicates the area of the aorta-tracheal fistula 

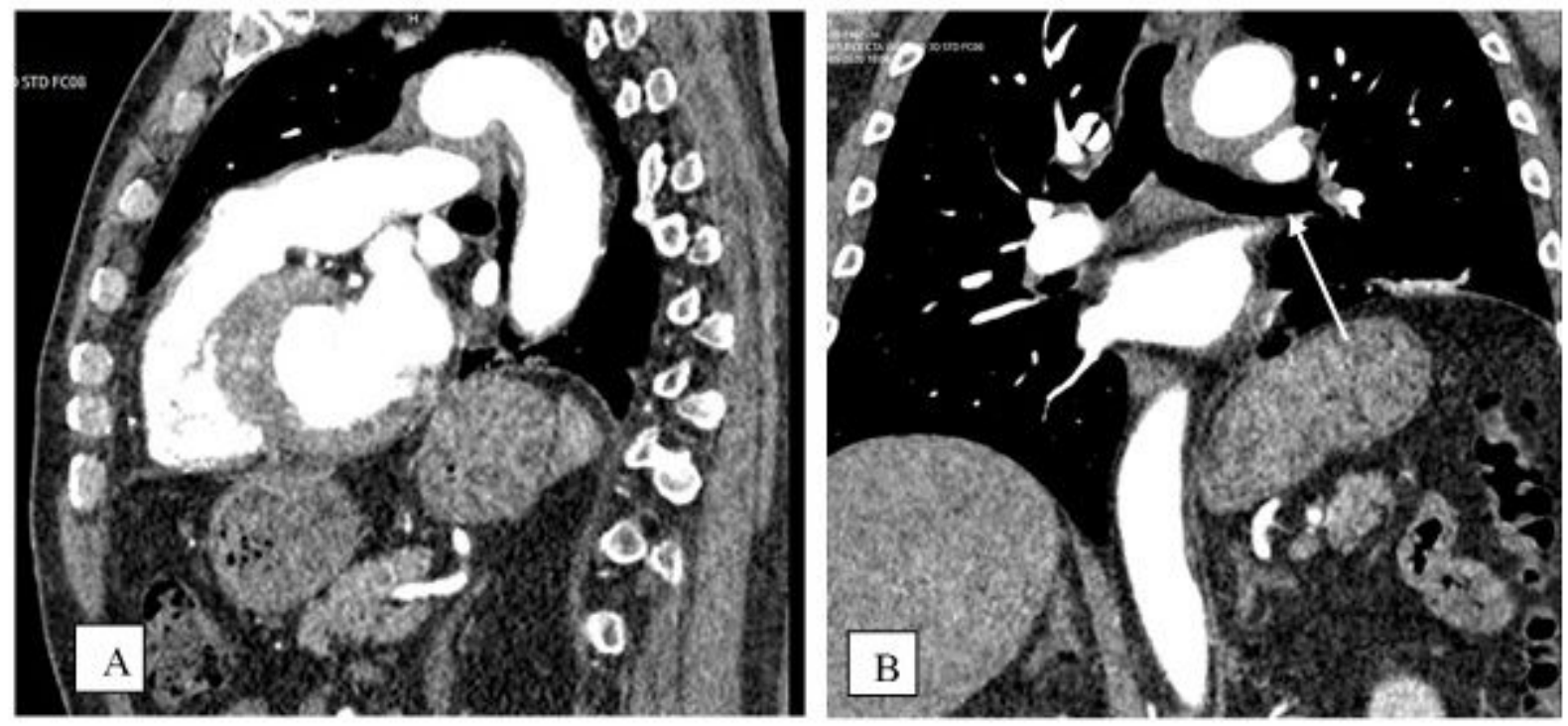

Figure 3

Chest CT scan 3 months after surgery: A) the aortic prosthesis is functioning well; B) the patency of trachea the left main bronchus is restored (the left main bronchus is indicated by a white arrow) 